\title{
Transient Heat Stress Compromises the Resistance of Wheat (Poales: Poaceae) Seedlings to Hessian Fly (Diptera: Cecidomyiidae) Infestation
}

\author{
YALEAKA CURRIE, ${ }^{1}$ JOHN MOCH, ${ }^{1}$ JOSHUA UNDERWOOD,${ }^{1}$ HAMZAH KHARABSHEH, ${ }^{1}$ \\ AMY QUESENBERRY, ${ }^{1}$ RISA MIYAGI,${ }^{1}$ CAROLYN THOMAS,${ }^{1}$ MELANIE BONEY, ${ }^{1}$ \\ SAMANTHA WOODS, ${ }^{1}$ MING-SHUN CHEN, ${ }^{2}$ AND LIECENG ZHU ${ }^{1,3}$
}

\begin{abstract}
J. Econ. Entomol. 107(1): 389-395 (2014); DOI: http://dx.doi.org/10.1603/EC13261
ABSTRACT Heat stress exerts a profound impact on the resistance of plants to parasites. In this research, we investigated the impact of an acute transient heat stress on the resistance of the wheat line 'Molly,' which contains the R gene H13, to an avirulent Hessian fly (Mayetiola destructor (Say)) population. We found that a significant portion of Molly seedlings stressed at $40^{\circ} \mathrm{C}$ for $6 \mathrm{~h}$ during or after the initial Hessian fly larval attack became susceptible to otherwise avirulent insects, whereas unstressed control plants remained $100 \%$ resistant. Specifically, $77.8,73.3,83.3$, and $46.7 \%$ of plants heat stressed at $0,6,12$, and $24 \mathrm{~h}$, respectively, after the initial larval attack became susceptible. Biochemical analysis revealed that heat stress caused a transient decrease in 12-oxo-phytodienoic acid, but an increase in salicylic acid accumulation in Molly plants. The change in phytohormones after heat stress and Hessian fly infestation was not observed in 'Newton,' a near-isogenic but Hessian fly susceptible wheat line. Instead, heat stress caused a relatively prolonged reduction in palmitoleic acid. The role of phytohormones in heat-induced loss of wheat resistance was discussed.
\end{abstract}

KEY WORDS heat stress, wheat, Hessian fly, loss of resistance, phytohormone

Heat stress exerts profound impacts on plants. Heat alters membrane fluidity and permeability (Alfonso et al. 2001, Sangwan et al. 2002), influences enzyme activities (Vierling 1991, Kampinga et al. 1995), induces production of active oxygen species (Suzuki and Mittler 2006), reduces photosynthesis and carbon gain (Way and Sage 2008), and modifies growth and reproduction (Cheikh and Jones 1994, Zinn et al. 2010). The responses of plants to heat stress at multiple levels reflect the adjustments of plants trying to adapt, survive, and develop in stressed environments (Garrett et al. 2006). In this process, the ability of plant to defend against biotic stresses may be affected. In plant-pathogen interactions, heat stress often reduces plant immunity and inhibits disease resistance (Zhu et al. $2010 \mathrm{~b}$ ). When temperature was raised from 22 to $28^{\circ} \mathrm{C}$, Arabidopsis plants became more susceptible to virulent Pseudomonas syringae pv. tomato (Pst) DC3000 (Wang et al. 2009). The N gene that conveys resistance in tomato plants to tobacco mosaic virus (TMV) is effective at $22^{\circ} \mathrm{C}$, but inactivated at $30^{\circ} \mathrm{C}$ (Whitham et al. 1996). In plant-insect interactions, higher temperature may decrease or increase plant resistance. Re-

\footnotetext{
${ }^{1}$ Department of Biological Sciences, Fayetteville State University, 1200 Murchison Rd., Fayetteville, NC 28301.

${ }^{2}$ Department of Entomology, Hard Winter Wheat Genetics Research Unit, Center for Grain and Animal Health Research, USDAARS, 4008 Throckmorton Hall, Kansas State University, Manhattan, KS 66506

${ }^{3}$ Corresponding author, e-mail: lzhu@uncfsu.edu.
}

sistance of alfalfa varieties to spotted alfalfa aphids is less effective at higher temperatures (Isaak et al. 1963), whereas in sorghums, expressions of tolerance and antixenosis to greenbug biotypes $\mathrm{C}$ and $\mathrm{E}$ are greater at $30^{\circ} \mathrm{C}$ than at $26^{\circ} \mathrm{C}$ (Thindwa and Teetes 1994).

The Hessian fly, Mayetiola destructor (Say), is one of the most destructive pests of wheat, Triticum aestivium L., in North America and North Africa (Berzonsky et al. 2003). Wheat and Hessian fly populations interact in a typical gene-for-gene manner (Hatchett and Gallun 1970). Attacks from a specific avirulent Hessian fly larva to a wheat plant containing an effective $R$ gene invoke vigorous defense responses from the plant, resulting in the death of the attacking insect (Shukle et al. 1990). Most, if not all, Hessian fly $R$ genes are temperature-sensitive even though the effective range of temperatures varies from gene to gene. For example, effectiveness of resistance conferred by H10, H11, and $\mathrm{H12}$ can be reduced at $24^{\circ} \mathrm{C}$ (Buntin et al. 1990), while resistance in synthetic hexaploid wheat derived from Triticum tauschii (Coss.) Schmal. is significantly reduced at $31^{\circ} \mathrm{C}$ (Tyler and Hatchett 1983). The reduction of wheat resistance to Hessian fly induced by heat stress may be transitory, and the resistance can be restored after the plants recovered from heat stress (Liu et al. 2013). The loss of host resistance may reflect compromised plant defense mechanisms under heat stress conditions.

We are interested in the impact of transient heat stress on the resistance of wheat plants to Hessian fly 
Table 1. Treatments for the analysis of phytohormone and fatty acid profiles in Molly and Newton seedlings

\begin{tabular}{cl}
\hline \hline Treatment & Treatment description \\
\hline $\mathrm{A}$ & Control, plants grew under room temp and normal light and dark cycle before sampling. \\
$\mathrm{B}$ & Plants grew under room temp, but were placed in the dark for $6 \mathrm{~h}$ before sampling. \\
$\mathrm{C}$ & Plants were placed under $40^{\circ} \mathrm{C}$ for $6 \mathrm{~h}$ in the dark; samples were collected immediately after completion \\
of the heat treatment. & Plants were placed under $40^{\circ} \mathrm{C}$ for $6 \mathrm{~h}$ in the dark; samples were collected at $12 \mathrm{~h}$ after completion of the \\
h & heat treatment.
\end{tabular}

infestation and the molecular mechanisms underlining heat-induced loss of host resistance. On attacks from avirulent Hessian fly larvae, resistant wheat rapidly mobilizes membrane lipids and other resources, leading to altered phytohormone and fatty acid profiles (Zhu et al. 2008, 2010, 2012). Many phytohormones regulating plant defense responses to parasites are also involved in plant responses to heat stress. For example, pretreatment of plants with salicylic acid (SA) increases basal thermotolerance of Arabidopsis (Larkindale et al. 2005); the cpr5-1 mutant exhibiting constitutive activation of SA, jasmonic acid (JA), and ethylene (ET) signaling pathways, displays enhanced tolerance to heat stress (Clarke et al. 2009); applying wild-type Arabidopsis with heat stress leads to increased accumulation of 12-oxo-phytodienoic acid (OPDA) along with JA and a JA-isoleucine (JA-Ile) conjugate in the plants (Clarke et al. 2009). Fatty acids are biosynthetic precursors of JA and OPDA, and they are degradation products of membrane lipids that are sensitive to various stress factors (Kachroo and Kachroo 2009). Therefore, fatty acids are profoundly involved in plant defense against parasites and adaptation to heat stress (Stintzi et al. 2001, ChandraShekara et al. 2007, Kachroo and Kachroo 2009, Wang et al. 2010). The importance of phytohormones and fatty acids in plant defense responses to both abiotic and biotic stresses leads us to ask the question: What has heat stress done to the profiles of phytohormones and fatty acids that might contribute to the loss of plant resistance? We are particularly interested in the effect of acute heat stress transiently introduced to plants for two reasons: 1) Changes caused by acute heat stress at molecular levels are presumably more significant than that of mild heat stress and thereby can be easily identified; 2) Acute, but transient, heat stress occurs often in natural environments, but its effect has not been well studied in the context of plant-parasite interactions. The objectives of this research are: 1) To evaluate the effect of transient heat stress $\left(40^{\circ} \mathrm{C}\right.$ for $\left.6 \mathrm{~h}\right)$ on the resistance of wheat plants to Hessian fly infestation; 2) to profile the phytohormones and fatty acids in a resistant wheat line under heat stress. Our findings will add to the understanding of heat-induced loss of resistance to parasites in plants.

\section{Materials and Methods}

Plant and Insect Materials. Wheat genotypes 'Molly' and 'Newton' were used in the study. Molly contains $R$ gene $H 13$ and is a near-isogenic back-cross line of the susceptible wheat Newton (Patterson et al.
1994). The Hessian fly population called "White eye" was used for infestation of plants. The White eye population is avirulent to Molly at room temperature or below, but virulent to Newton under the same condition (Shukle and Stuart 1993).

Plant Preparation and Infestation. Fifteen pregerminated Molly seeds were planted in each pot of 10 $\mathrm{cm}$ in diameter. The pots were placed in a growth cart under room temperature $\left(23^{\circ} \mathrm{C}\right)$. The cart was equipped with growth lights set at a photoperiod of 14:10 (L:D) h. Plants that significantly lagged in development were removed from the pots before infestation. At 1.5 leaf stage, approximately eight mated female Hessian fly adults were released onto plants confined within a cage with screen. These flies immediately laid eggs on wheat leaves. After eggs hatched in $\approx 72 \mathrm{~h}$, larvae crawled down to the bottom of plants, established between the first and the second leaf sheaths, and fed on the second leaf sheath. To determine the time when Hessian fly larvae initiated attacks to plants, a set of infested plants under the same environment were dissected and observed hourly under a dissection microscope at the fourth day after infestation. The time at which Hessian larvae were first seen at the base of examined plants was defined as the time for the initial attack.

Heat Treatment of Molly Plants. Plants were placed in an incubator preadjusted at $40^{\circ} \mathrm{C}$ for $6 \mathrm{~h}$ starting at $0,6,12,24$, and $48 \mathrm{~h}$, respectively, after the initial Hessian fly larval attack. Control plants were treated the same way, but without heat stress. All plants were moved back to room temperature under the designated light and dark cycle after treatments. Each treatment was repeated three times.

Resistance Evaluation of Molly Plants. Seven days after the initial larval attack, each plant in a pot was dissected and checked for dead and live larvae under a dissecting microscope. Plants containing live larvae were designated susceptible, and plants with only dead larvae were resistant. Mean percentages of susceptible plants were calculated and compared among treatments. Meanwhile, numbers of live larvae in susceptible plants were counted, and the percentage of surviving larvae was calculated as the total number of live larvae divided by the total number of larvae in the susceptible plants in a treatment.

Heat Treatment of Molly and Newton for Phytohormone and Fatty Acid Analysis. At 1.5 leaf stage, Molly and Newton plants were subject to the following treatments as described in the Table 1. Treatment A is the control. Owing to limitation of equipment, heat stress was conducted in an incubator with no light 
supply; therefore, treatment B was established to eliminate the effect of dark treatment accompanying the process of heat treatment. Comparison among treatments B, C, and D allows us to examine the effects of heat stress either immediately after completion of the heat treatment, or $12 \mathrm{~h}$ after completion of the heat treatment. The experiments were arranged following complete randomized block design (CRBD) with four replicates. Samples were collected from the second leaf sheath, the location where larval attacks would have taken place if plants were infested. Samples from the same pot were pooled into a preweighed 1.5-ml Eppendorf tube placed on ice. The samples were then weighed, immediately placed into liquid nitrogen, and stored in a $-80^{\circ} \mathrm{C}$ freezer until the extraction of phytohormone and fatty acids.

Extraction and Analysis of Phytohormones and Fatty Acids. Chemical ionization-gas chromatography and mass spectrometry (GC-CI-MS) was used to analyze phytohormones and fatty acids. The measurement was carried out in the Kansas Lipidomics Research Center at Kansas State University following the procedure described by Schmelz et al. (2004). Briefly, frozen tissue was ground in liquid nitrogen and poured into $1.5-\mathrm{ml}$ FastPrep tubes containing $\approx 1 \mathrm{~g}$ of $1.1-\mathrm{mm}$ Zirmil beads (Saint-Gobain ZirPro, Mountainside, $\mathrm{NJ})$. Three hundred microliter of 1-propanol: $\mathrm{H}_{2} \mathrm{O}$ : $\mathrm{HCl}$ (2: 1: 0.005, vol:vol:vol) extraction buffer and a mixture of internal standards (100 ng of each phytohormone and fatty acid) were added to the samples. Tissues were pulverized by a FastPrep FP 120 homogenizer (Qbiogene, Carlsbad, CA). After being homogenized for $10 \mathrm{~s}, 1 \mathrm{ml}$ dichloromethane $\left(\mathrm{CH}_{2} \mathrm{Cl}_{2}\right)$ was added to each sample, and the samples were rehomogenized and centrifuged for $3 \mathrm{~min}$ at room temperature at $12,000 \mathrm{rpm}$. For the derivatization, the bottom $\mathrm{CH}_{2} \mathrm{Cl}_{2}$ :1-propanol layer was transferred to a 4-ml glass vial in which $20 \mu \mathrm{l}$ of $400 \mathrm{mM}$ trimethylsilyldiazomethane in $\mathrm{CH}_{2} \mathrm{Cl}_{2}$ was added. The samples were vortexed and incubated for $30 \mathrm{~min}$ at room temperature to allow methyl ester formation. Once methyl ester formation was complete, $20 \mu \mathrm{l}$ of $400 \mathrm{mM}$ acetic acid in $\mathrm{CH}_{2} \mathrm{Cl}_{2}$ was added to quench the reaction. The samples were vortexed again and then incubated for $30 \mathrm{~min}$ at room temperature. Finally, vapor phase extraction was performed to the samples. Super Q filters (Alltech Associates Inc., Deerfield, IL) were used to collect the phytohormones and fatty acids. The Super Q filter was placed in the high temperature septum of the vial. A needle supplying a stream of nitrogen gas was inserted into the septum and a vacuum line was connected to the Super $Q$ filter. The vial was placed in a $70^{\circ} \mathrm{C}$ heating block until the solvent evaporated. The dry vial was then transferred to a heating block at $200^{\circ} \mathrm{C}$ for 2 min to recover less volatile compounds. The Super Q filters were eluted into inserts of $\mathrm{GC}$ vials with $150 \mu \mathrm{l}$ of $\mathrm{CH}_{2} \mathrm{Cl}_{2}$ and analyzed by gas chromatography-mass spectrometry (GC-MS, Agilent Technologies, Wilmington, DE). GC-MS analysis of the derivatized extracts was performed on an Agilent model 6890N GC coupled to an Agilent model 5975 quadrupole mass selective detec-

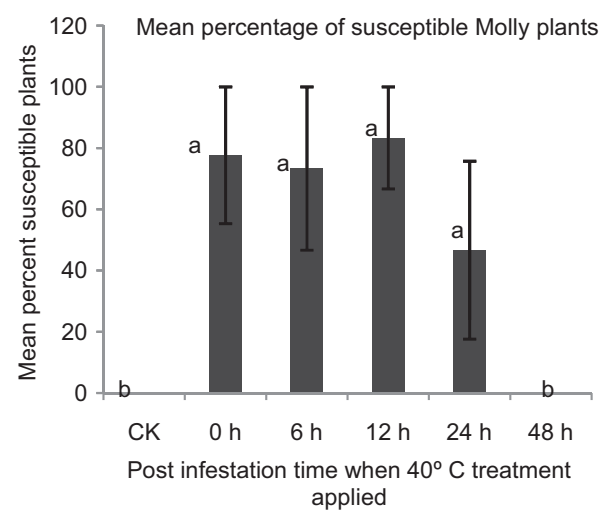

Fig. 1. Mean percentage $\pm \mathrm{SE}$ of plants that became susceptible under different treatments. CK-no heat treatment; $0,6,12,24$, and $48 \mathrm{~h}$-plants were treated with $40^{\circ} \mathrm{C}$ for $6 \mathrm{~h}$ starting at $0,6,12,24$, and $48 \mathrm{~h}$, respectively, after the initial larval attack. Scale bars marked with different letters are significantly different in values at $\alpha=0.01 ; n=3$.

tor (MSD). Separation was achieved on a DB-1MS fused silica capillary column. One-microliter samples were injected in a splitless mode with an Agilent 7683B series autosampler. The MS was operated in the chemical ionization (CI) mode with methane as the ionization gas. The phytohormones and fatty acids, as well as their corresponding internal standards, were monitored using a selective ion for each analyte (SIM mode) as follows: SA (153), JA (225), OPDA (307), abscisic acid (ABA) (279), indole-3-acetic acid (IAA) (190), benzoic acid (BA, 137), cinnamic acid (CA, 163), palmitoleic acid (FA16:1, 269), linoleic acid (FA18:2, 295), $\alpha$-linolenic acid (FA18:3, 293), oleic acid (FA18:1, 297), nonadecanoic acid (FA19:0, 313), H6-SA (157), dhJA (227), and H5-IAA (195). Quantifications of FA18:1, FA18:2, FA18:3, and OPDA were based on FA19:0. Data were acquired and processed with Agilent Chemstation software (Agilent Technologies, Santa Clara, CA). The concentrations were represented as nanogram per milligram fresh sample weight (ng/mg FW). The relative concentration was derived by dividing the concentration ( $\mathrm{ng} / \mathrm{mg} \mathrm{FW}$ ) of each compound with the total concentration of the 11 compounds in a treatment for each replicate.

Statistical Analysis. Outliers were removed from the data based on the results of Dixon's Q test (Dixon 1950) before further statistical analysis. Analysis of variance (ANOVA) was conducted using PROC GLM (SAS Institute 1999). Means were compared, and the significance of differences was determined by least significant difference (LSD; $\alpha=0.01$ ).

\section{Results}

Resistance of Molly Wheat Seedlings Under Heat Stress. Without heat treatment, larvae in Molly seedlings were all dead at the time of examination, and the plants exhibited complete resistance (Fig. 1). When plants were exposed to $40^{\circ} \mathrm{C}$ for $6 \mathrm{~h}$ starting at $0,6,12$, and $24 \mathrm{~h}$, respectively, after the initial larval attack, an 


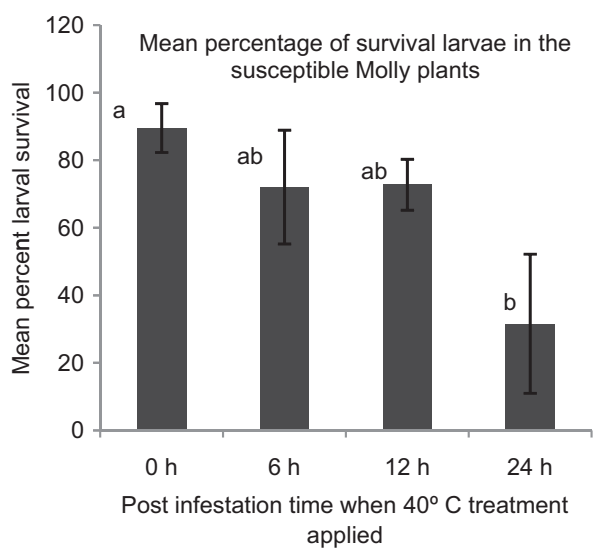

Fig. 2. Mean percentage $\pm \mathrm{SE}$ of survived larvae in the heat-induced susceptible plants under different treatments. $0,6,12$, and $24 \mathrm{~h}-$ plants were treated with $40^{\circ} \mathrm{C}$ for $6 \mathrm{~h}$ starting at $0,6,12$, and $24 \mathrm{~h}$, respectively, after the initial larval attack. Scale bars marked with different letters are significantly different in values at $\alpha=0.01 ; n=3$.

average of $78,73,83$, and $47 \%$ of plants became susceptible (Fig. 1). No plant became susceptible when the heat treatment was applied at $48 \mathrm{~h}$ after the initial larval attack. It seemed that less plants lost resistance and less larvae survived in plants heat stressed at $24 \mathrm{~h}$ than stressed at earlier time points (Figs. 1 and 2).

Phytohormone and Fatty Acid Levels in Control Plants. Eleven compounds were analyzed in Molly and Newton plants. Those compounds are phytohormones including SA, JA, IAA, and ABA, the precursors in SA synthesis BA and CA, the precursor in JA synthesis OPDA, and fatty acids FA16:1, FA18:3, FA18:2, and FA18:1. In the control plants growing under room temperature and normal light and dark cycles (Treatment A), significant differences in the concentrations of the different compounds exist in each line (Molly: $F=110.28 ; \mathrm{df}=10,30 ; P<0.0001 ;$ Newton: $F=20.74$; $\mathrm{df}=10,20 ; P<0.0001)$. FA18:1 was the most abundant compound followed by OPDA and FA16:1 in both lines, while IAA and ABA were the least abundant

Table 2. Mean concentration \pm SD (ng/mg FW) of phytohormones and fatty acids in Molly and Newton

\begin{tabular}{lcc}
\hline \hline \multirow{2}{*}{ Compound } & \multicolumn{2}{c}{ Mean concn \pm SD $(\mathrm{ng} / \mathrm{mg}$ FW $)$} \\
\cline { 2 - 3 } & \multicolumn{1}{c}{ Molly } & \multicolumn{1}{c}{ Newton } \\
\hline BA & $0.37 \pm 0.040 \mathrm{~d}$ & $1.53 \pm 0.187 \mathrm{bcd}$ \\
SA & $0.18 \pm 0.041 \mathrm{~d}$ & $0.29 \pm 0.021 \mathrm{ed}$ \\
CA & $0.11 \pm 0.022 \mathrm{~d}$ & $0.24 \pm 0.077 \mathrm{ed}$ \\
JA & $0.41 \pm 0.041 \mathrm{~d}$ & $0.59 \pm 0.173 \mathrm{cde}$ \\
IAA & $0.06 \pm 0.023 \mathrm{~d}$ & $0.19 \pm 0.064 \mathrm{ed}$ \\
ABA & $0.07 \pm 0.016 \mathrm{~d}$ & $0.11 \pm 0.033 \mathrm{e}$ \\
OPDA & $2.61 \pm 0.564 \mathrm{~b}$ & $1.92 \pm 1.241 \mathrm{bc}$ \\
FA16:1 & $1.56 \pm 0.216 \mathrm{c}$ & $2.11 \pm 0.324 \mathrm{~b}$ \\
FA18:3 & $1.48 \pm 0.501 \mathrm{c}$ & $1.14 \pm 0.073 \mathrm{bcd}$ \\
FA18:2 & $0.38 \pm 0.054 \mathrm{~d}$ & $0.22 \pm 0.037 \mathrm{ed}$ \\
FA18:1 & $4.26 \pm 0.565 \mathrm{a}$ & $5.24 \pm 1.282 \mathrm{a}$ \\
\hline
\end{tabular}

In the same column, numbers marked with different letters are significantly different at $\alpha=0.01 ; n=4$ for each mean value in Molly, and $n=3$ in Newton.
Table 3. Mean relative concentration \pm SD of phytohormones and fatty acids

\begin{tabular}{llc}
\hline \multirow{2}{*}{ Compound } & \multicolumn{2}{c}{ Mean relative concn \pm SD } \\
\cline { 2 - 3 } & \multicolumn{1}{c}{ Molly } & Newton \\
\hline BA & $\mathbf{0 . 0 3} \pm \mathbf{0 . 0 0 2}$ & $\mathbf{0 . 1 1} \pm \mathbf{0 . 0 1 5}$ \\
SA & $0.02 \pm 0.002$ & $0.02 \pm 0.002$ \\
CA & $0.01 \pm 0.001$ & $0.02 \pm 0.006$ \\
JA & $0.04 \pm 0.004$ & $0.04 \pm 0.014$ \\
IAA & $0.01 \pm 0.001$ & $0.01 \pm 0.004$ \\
ABA & $0.01 \pm 0.002$ & $0.01 \pm 0.003$ \\
OPDA & $0.23 \pm 0.026$ & $0.14 \pm 0.095$ \\
FA16:1 & $0.14 \pm 0.015$ & $0.16 \pm 0.021$ \\
FA18:3 & $0.13 \pm 0.026$ & $0.08 \pm 0.007$ \\
FA18:2 & $\mathbf{0 . 0 3} \pm \mathbf{0 . 0 0 3}$ & $\mathbf{0 . 0 2} \pm \mathbf{0 . 0 0 2}$ \\
FA18:1 & $0.37 \pm 0.018$ & $0.38 \pm 0.077$ \\
\hline
\end{tabular}

The relative concentration was derived by dividing the concentration (ng/mg FW) of each compound with the total concentration of the 11 compounds in a treatment for each replicate.

Bold faced numbers indicate that the mean relative concentrations are statistically different between Molly and Newton at $\alpha=0.01$.

$n=4$ for each mean value in Molly, and $n=3$ in Newton.

(Table 2). Mean concentrations of the phytohormones SA and JA appeared to be higher than those of IAA and ABA. Relative concentration of all compounds except FA18:2 and BA were similar between Molly and Newton (Table 3). FA18:2 was higher in Molly $(F=196.00 ; \mathrm{df}=1,2 ; P=0.0051)$, while BA was higher in Newton $(F=121.75$; df $=1,2 ; P=0.0081)$.

Impact of Heat Stress on Phytohormones and Fatty Acids. In Molly, the result of ANOVA on the concentration $(\mathrm{ng} / \mathrm{mg} \mathrm{FW})$ of each compound indicated that the effect of the treatment was significant only in SA $(F=40.23 ; \mathrm{df}=3,9 ; P<0.0001)$ and OPDA $(F=17.42$; df $=3,9 ; P=0.0004 ;$ Table 4$)$. The heat stress caused a temporary increase in accumulation of SA (Fig. 3) and a decrease in OPDA (Fig. 4), and the effect diminished at $12 \mathrm{~h}$ after the recovery of plants from heat stress.

In Newton, however, the effect of heat stress was significant only in the concentration of FA16:1 $(F=$ 30.97; $\mathrm{df}=3,6 ; P=0.0005$; Table 5). The heat stress caused a significant reduction in the accumulation of

Table 4. ANOVA results on concentrations $(\mathrm{ng} / \mathrm{mg} \mathrm{FW})$ of the 11 phytohormones and fatty acids obtained from the control and treated Molly seedlings

\begin{tabular}{|c|c|c|c|c|c|c|}
\hline \multirow{3}{*}{ Compound } & \multirow{2}{*}{\multicolumn{2}{|c|}{ Overall ANOVA }} & \multicolumn{4}{|c|}{ Main effect } \\
\hline & & & \multicolumn{2}{|c|}{ Treatment } & \multicolumn{2}{|c|}{ Replicate } \\
\hline & $F$ & $P$ & $F$ & $P$ & $F$ & $P$ \\
\hline SA & 20.94 & $<0.0001$ & 40.23 & $<0.0001$ & 1.65 & 0.2461 \\
\hline JA & 0.86 & 0.5594 & 1.32 & 0.3273 & 0.39 & 0.7612 \\
\hline $\mathrm{CA}$ & 1.33 & 0.3364 & 1.40 & 0.3047 & 1.26 & 0.3461 \\
\hline BA & 1.04 & 0.4572 & 0.88 & 0.4869 & 1.21 & 0.3611 \\
\hline IAA & 1.48 & 0.2878 & 2.68 & 0.1102 & 0.27 & 0.8436 \\
\hline $\mathrm{ABA}$ & 0.36 & 0.8838 & 0.36 & 0.7801 & 0.36 & 0.7801 \\
\hline OPDA & 8.91 & 0.0023 & 17.42 & 0.0004 & 0.41 & 0.7518 \\
\hline FA16:1 & 1.46 & 0.2922 & 2.39 & 0.1365 & 0.53 & 0.6706 \\
\hline FA18:1 & 4.58 & 0.0210 & 5.43 & 0.0208 & 3.72 & 0.0545 \\
\hline FA18:2 & 1.13 & 0.4149 & 1.29 & 0.3356 & 0.98 & 0.4452 \\
\hline FA18:3 & 3.19 & 0.0580 & 5.04 & 0.0255 & 1.33 & 0.3231 \\
\hline
\end{tabular}

Degree of freedom for $F$ test: Overall ANOVA df $=6$, 9; Treatment df $=3,9$; Replicate $\mathrm{df}=3,9$. 


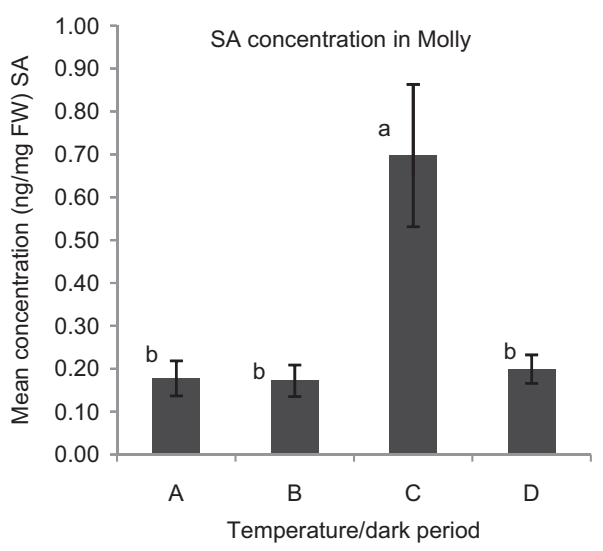

Fig. 3. Mean concentrations $(\mathrm{ng} / \mathrm{mg} \mathrm{FW} \pm \mathrm{SD})$ of $\mathrm{SA}$ in different treatments in Molly. (A) Room temperature + normal light and dark cycle; (B) room temperature $+6 \mathrm{~h}$ in the dark; (C) 6 h heat treatment in the dark, and samples were collected immediately after completion of the heat treatment; (D) $6 \mathrm{~h}$ heat treatment in the dark, and samples were collected at $12 \mathrm{~h}$ after completion of the heat treatment. Scale bars marked with different letters are significantly different in values at $\alpha=0.01 ; n=4$.

FA16:1, and the effect remained at $12 \mathrm{~h}$ after the recovery of plants from heat stress (Fig. 5).

\section{Discussion}

Our results indicate that acute transient heat stress can induce the loss of $R$ gene-mediated resistance in wheat to Hessian fly infestation. This occurs only during the first $24 \mathrm{~h}$ after infestation, probably because the defense mechanisms of plants have not yet been fully established during this period of time.

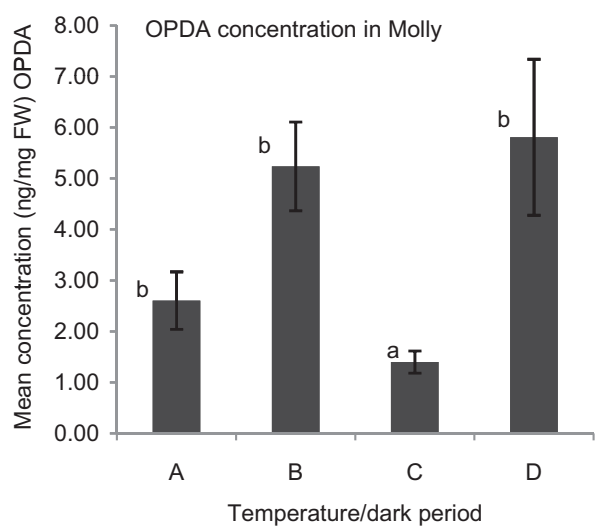

Fig. 4. Mean concentrations (ng/mg FW $\pm \mathrm{SD}$ ) of OPDA in different treatments in Molly. (A) Room temperature + normal light and dark cycle; (B) room temperature $+6 \mathrm{~h}$ in the dark; (C) $6 \mathrm{~h}$ heat treatment in the dark, and samples were collected immediately after the heat treatment; (D) $6 \mathrm{~h}$ heat treatment in the dark, and samples were collected at $12 \mathrm{~h}$ after completion of the heat treatment. Scale bars marked with different letters are significantly different in values at $\alpha=0.01 ; n=4$.
Table 5. ANOVA results on concentrations (ng/mg FW) of the 11 phytohormones and fatty acids obtained from the control and treated Newton seedlings

\begin{tabular}{|c|c|c|c|c|c|c|}
\hline \multirow{3}{*}{ Compound } & \multirow{2}{*}{\multicolumn{2}{|c|}{$\begin{array}{l}\text { Overall } \\
\text { ANOVA }\end{array}$}} & \multicolumn{4}{|c|}{ Main effect } \\
\hline & & & \multicolumn{2}{|c|}{ Treatment } & \multicolumn{2}{|c|}{ Replicate } \\
\hline & $F$ & $P$ & $F$ & $P$ & $F$ & $P$ \\
\hline SA & 5.10 & 0.0340 & 9.50 & 0.0107 & 0.87 & 0.5066 \\
\hline JA & 1.23 & 0.4046 & 2.05 & 0.2087 & 0.19 & 0.9006 \\
\hline $\mathrm{CA}$ & 3.01 & 0.1029 & 5.41 & 0.0384 & 0.47 & 0.7113 \\
\hline $\mathrm{BA}$ & 1.53 & 0.3090 & 2.49 & 0.1578 & 0.64 & 0.6182 \\
\hline IAA & 2.83 & 0.1157 & 2.61 & 0.1462 & 1.14 & 0.4073 \\
\hline ABA & 1.41 & 0.3433 & 1.28 & 0.3641 & 0.93 & 0.4807 \\
\hline OPDA & 1.56 & 0.3003 & 2.55 & 0.1521 & 0.66 & 0.6071 \\
\hline FAl6:1 & 16.37 & 0.0017 & 30.97 & 0.0005 & 0.81 & 0.5317 \\
\hline FA18:1 & 0.22 & 0.9550 & 0.13 & 0.9394 & 0.24 & 0.8648 \\
\hline FA18:2 & 0.61 & 0.7170 & 0.36 & 0.7815 & 0.41 & 0.7529 \\
\hline FA18:3 & 0.82 & 0.5921 & 0.88 & 0.5020 & 0.52 & 0.6847 \\
\hline
\end{tabular}

Degree of freedom for $F$ test: Overall ANOVA df $=6$, 6; Treatment $\mathrm{df}=3,6$; Replicate $\mathrm{df}=3,6$.

Under the same intensity and duration of heat stress, the accumulation of SA in Molly seedlings was enhanced (Fig. 3). Increase in SA was observed in Molly infested with avirulent biotype in incompatible interactions (Zhu et al. 2010, 2011). Given the importance of SA in regulating plant responses to biotic and abiotic stresses, the fact that heat stress and avirulent Hessian fly infestation induce similar responses in SA accumulation in the same tissue of the same wheat line suggests that the increase of SA may be a general response of wheat plants to both biotic and abiotic stresses. On the contrary, the accumulation of OPDA in Molly was significantly reduced under heat stress (Fig. 4). OPDA's roles in plant resistance to insect parasites have been recognized in recent years (Stintzi et al. 2001; Zhu et al. 2010a, 2011); however,

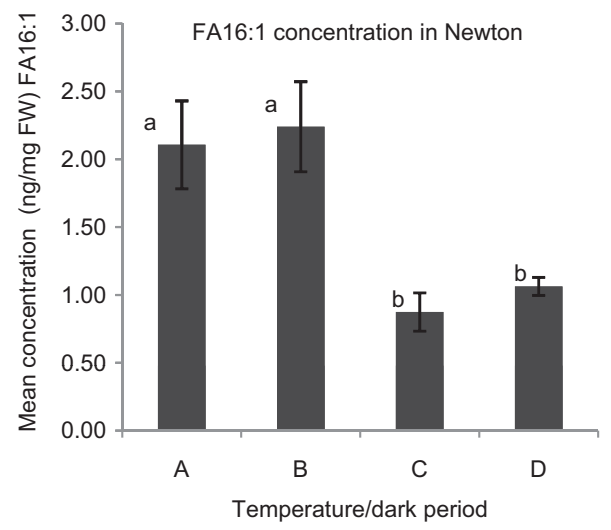

Fig. 5. Mean concentrations (ng/mg FW $\pm \mathrm{SD}$ ) of FA16:1 in different treatments in Newton. (A) Room temperature + normal light and dark cycle; (B) room temperature $+6 \mathrm{~h}$ in the dark; (C) $6 \mathrm{~h}$ heat treatment in the dark, and samples were collected immediately after completion of the heat treatment; (D) $6 \mathrm{~h}$ heat treatment in the dark, and samples were collected at $12 \mathrm{~h}$ after completion of the heat treatment. Scale bars marked with different letters are significantly different in values at $\alpha=0.01 ; n=4$ for treatments $\mathrm{C}$ and $\mathrm{D} ; n=3$ for treatment $\mathrm{A} ; n=2$ for treatment $\mathrm{B}$. 
few studies related OPDA to plant responses to heat stress. Clarke et al. (2009) reported that applying heat stress on Arabidopsis caused increased accumulation of OPDA, which is inconsistent with our results. The discrepancy could be attributed to the difference in species of the plants used in the study or the tissue types collected for analysis. Nonetheless, the response of Molly seedlings to heat stress in OPDA accumulation is contradictory to its response to avirulent Hessian fly infestation, in which OPDA was highly induced in the incompatible interaction (Zhu et al. 2010a, 2011). Such comparison seems to suggest that higher level of OPDA accumulation is critical in the effectiveness of wheat's resistance, and that the reduction of OPDA accumulation caused by heat stress may contribute to the loss of resistance of wheat plants to Hessian fly infestation.

Newton, however, responds to heat stress differently from Molly. Heat stress did not affect ODPA and SA accumulations in Newton plants, but significantly reduced FA16:1 accumulation, and the reduction remained at $12 \mathrm{~h}$ after the recovery of plants from the heat stress treatment (Fig. 5). FA16:1 is involved in plant responses to biotic and abiotic stresses in various species (Xing and Chin 2000, Liu and Huang 2004, Smith et al. 2010); however, its role in wheat-Hessian fly interactions has not yet been identified. Nevertheless, our results reveal that Newton seedlings respond to heat stress differently from Molly in the accumulations of SA, OPDA, and FA16:1. Given that Molly and Newton are near-isogenic lines that differ in their reactions to Hessian fly infestation, the different responses in accumulations of phytohormones and fatty acids may, to a certain extent, relate to their abilities to interact with Hessian fly infestation.

\section{Acknowledgment}

We thank Thilani Samarakoon in Kansas Lipidomics Research Center at Kansas State University for profiling phytohormones and fatty acids. This research was supported by 2012 and 2013 Fayetteville State University Title III HBCU Masters Degree STEM Program Faculty Research MiniGrants, 2012 Summer Faculty Research Stipend Program, and a grant from the National Science Foundation HRD Award \#1036257.

\section{References Cited}

Alfonso, M., I. Yruela, S. Almarcegui, E. Torrado, M. A. Perez, and R. Picorel. 2001. Unusual tolerance to high temperatures in a new herbicide-resistant D1 mutant from Glycine $\max (\mathrm{L}$.) Merr. cell cultures deficient in fatty acid desaturation. Planta 212: 573-582.

Berzonsky, W. A., H. Ding, S. D. Haley, M. O. Harris, R. J. Lamb, R.I.H. McKenzie, H. W. Ohm, F. L. Patterson, F. B. Peairs, D. R. Porter, et al. 2003. Breeding wheat for resistance to insects. Plant Breed. Rev. 22: 221-296.

Buntin, G. D., P. L. Bruckner, J. W. Johnson, and J. E. Foster. 1990. Effectiveness of selected genes for Hessian fly resistance in wheat. J. Agric. Entomol. 7: 283-291.

Chandra-Shekara, A. C., S. C. Venugopal, S. R. Barman, A. Kachroo, and P. Kachroo. 2007. Plastidial fatty acid levels regulate resistance gene-dependent defense signaling in Arabidopsis. Proc. Natl. Acad. Sci. U.S.A. 104: 72777282.

Cheikh, N., and R. J. Jones. 1994. Disruption of maize kernel growth and development by heat stress (Role of Cytokinin/Abscisic Acid Balance). Plant Physiol. 106: 45-51.

Clarke, S. M., S. M. Cristescu, O. Miersch, F.J.M. Harren, C. Wasternack, and L.A.J. Mur. 2009. Jasmonates act with salicylic acid to confer basal thermotolerance in Arabidopsis thaliana. New Phytol. 182: 175-187.

Dixon, W. J. 1950. Analysis of extreme values. Ann. Math. Stat. 21: 488-506.

Garrett, K. A., S. P. Dendy, E. E. Frank, M. N. Rouse, and S. E. Travers. 2006. Climate change effects on plant disease: genomes to ecosystems. Annu. Rev. Phytopathol. 44: 489509.

Hatchett, J. H., and R. L. Gallun. 1970. Genetics of the ability of the Hessian fly, Mayetiola destructor, to survive on wheat having different genes for resistance. Ann. Entomol. Soc. Am. 63: 1400-1407.

Isaak, A., E. L. Sorensen, and E. E. Ortman. 1963. Influence of temperature and humidity on resistance in alfalfa to the spotted alfalfa aphid and pea aphid. J. Econ. Entomol. 56: 53-57.

Kachroo, A., and P. Kachroo. 2009. Fatty acid-derived signals in plant defense. Annu. Rev. Phytopathol. 47: 153176.

Kampinga, H. H., J. F. Brunsting, G. J. Stege, P. W. Burgman, and A. W. Konings. 1995. Thermal protein denaturation and protein aggregation in cells made thermotolerant by various chemicals: role of heat shock proteins. Exp. Cell Res. 219: 536-546.

Larkindale, J., J. D. Hall, M. R. Knight, and E. Vierling. 2005. Heat stress phenotypes of Arabidopsis mutants implicate multiple signaling pathways in the acquisition of thermotolerance. Plant Physiol. 138: 882-897.

Liu, X., and B. Huang. 2004. Changes in fatty acid composition and saturation level for creeping bentgrass exposed to high soil temperature. J. Am. Soc. Hortic. 129: 795-801.

Liu, X., C. Khajuria, J. Li, H. N. Trick, L. Huang, B. S. Gill, G. R. Reeck, G. Antony, F. F. White, and M. Chen. 2013. Wheat Mds-1 encodes a heat-shock protein and governs susceptibility towards the Hessian fly gall midge. Nature Commun. 4. (doi:10.1038/ncomms3070).

Patterson, F. L., F. B. Maas, J. E. Foster, R. H. Ratcliffe, S. Cambron, G. Safranski, P. L. Taylor, and H. W. Ohm. 1994. Registration of eight Hessian fly resistant common winter wheat germplasm lines (Carol, Erin, Flynn, Iris, Joy, Karen, Lola, and Molly). Crop Sci. 34: 315-316.

Sangwan, V., B. L. Orvar, J. Beyerly, H. Hirt, and R. S. Dhindsa. 2002. Opposite changes in membrane fluidity mimic cold and heat stress activation of distinct plant MAP kinase pathways. Plant J. 31: 629-638.

SAS Institute. 1999. SAS/STAT user's guide, version 6. SAS Institute, Cary, NC.

Schmelz, E. A., J. Engelberth, J. H. Tumlinson, A. Block, and H. T. Alborn. 2004. The use of vapor phase extraction in metabolic profiling of phytohormones and other metabolites. Plant J. 39: 790-808.

Shukle, R. H., and J. J. Stuart. 1993. A novel morphological mutation in the Hessian fly, Mayetiola destructor. J. Hered. 84: 229-232.

Shukle, R. H., P. B. Grover, and J. E. Foster. 1990. Feeding of Hessian fly (Diptera: Cecidomyiidae) larvae on resistant and susceptible wheat. Environ. Entomol. 19: 494500.

Smith, C. M., X. Liu, L. J. Wang, X. Liu, M. S. Chen, S. Starkey, and J. Bai. 2010. Aphid feeding activates expression of a transcriptome of oxylipin-based defense signals 
in wheat involved in resistance to herbivory. J. Chem. Ecol. 36: 260-276.

Stintzi, A., H. Weber, P. Remond, J. Brows, and E. E. Farmer. 2001. Plant defense in the absence of jasmonic acid: the role of cyclopetenones. Proc. Natl. Acad. Sci. U.S.A. 98: 12837-12842.

Suzuki, N., and R. Mittler. 2006. Reactive oxygen species and temperature stresses: a delicate balance between signaling and destruction. Physiol. Plant 126: 45-51.

Thindwa, H. P., and G. L. Teetes. 1994. Effect of temperature and photoperiod on sorghum resistance to biotype $\mathrm{C}$ and E greenbug (Homoptera: Aphididae). J. Econ. Entomol. 87: 1366-1372.

Tyler, J. M., and J. H. Hatchett. 1983. Temperature influence on expression of resistance to Hessian fly (Diptera: Cecidomyiidae) in wheat derived from Triticum tauschii. J. Econ. Entomol. 76: 323-326.

Vierling, E. 1991. The roles of heat shock proteins in plants. Annu. Rev. Plant Physiol. Plant Mol. Biol. 42: $579-620$.

Wang, Y., Z. Bao, Y. Zhu, and J. Hua. 2009. Analysis of temperature modulation of plant defense against biotrophic microbes. Mol. Plant Microbe Interact. 22: $498-506$.

Wang, H. S., C. Yu, X. F. Tang, L. Y. Wang, X. C. Dong, and Q. W. Meng. 2010. Antisense-mediated depletion of tomato endoplasmic reticulum omega-3 fatty acid desaturase enhances thermal tolerance. J. Integr. Plant Biol. 52: 568-577.

Way, D. A., and R. F. Sage. 2008. Elevated growth temperatures reduce the carbon gain of black spruce [ (Picea mariana (Mill.) B.S.P.]. Glob. Chang. Biol. 14: 624-636.

Whitham, S., S. McCormick, and B. Baker. 1996. The N gene of tobacco confers resistance to tobacco mosaic virus in transgenic tomato. Proc. Natl. Acad. Sci. U.S.A. 93: $8776-8781$.

Xing, J., and C. Chin. 2000. Modification of fatty acids in eggplant affects its resistance to Verticillium dahliae. Physiol. Mol. Plant Pathol. 56: 217-225.

Zhu, L., X. M. Liu, X. Liu, R. Jeannotte, J. C. Reese, R. Welti, M. Harris, J. J. Stuart, and M. S. Chen. 2008. Hessian fly (Mayetiola destructor) attack causes a dramatic shift in carbon and nitrogen metabolism in wheat. Mol. Plant Microbe Interact. 21: 70-78.

Zhu, L., X. Liu, and M. S. Chen. 2010a. Differential accumulation of phytohormones in wheat seedlings attacked by avirulent and virulent Hessian fly (Diptera: Cecidomyiidae) larvae. J. Econ. Entomol. 103: 178-185.

Zhu, Y., W. Qian, and J. Hua. 2010b. Temperature modulates plant defense responses through NB-LRR proteins. PLoS Pathog. 6: el000844. (doi:10.1371/journal.ppat. 1000844).

Zhu, L., M. S. Chen, and X. Liu. 2011. Changes in phytohormones and fatty acids in wheat and rice seedlings in response to Hessian fly (Diptera: Cecidomyiidae) infestation. J. Econ. Entomol. 104: 1384-1392.

Zhu, L., X. M. Liu, H. Wang, C. Khajuria, J. C. Reese, J. Whitworth, R. Welti, and M-S Chen. 2012. Rapid mobilization of membrane lipids in wheat leaf-sheaths during incompatible interactions with Hessian fly. Mol. Plant Microbe Interact. 25: 920-930.

Zinn, K. E., M. Tunc-Ozdemir, and J. F. Harper. 2010. Temperature stress and plant sexual reproduction: uncovering the weakest links. J. Exp. Bot. 61: 1959-1968.

Received 30 May 2013; accepted 16 September 2013. 